\title{
Polymeric complexes and fragments of albumin in normal human plasma *
}

\author{
Bharati Kshirsagar, Barry Wilson and Roger C. Wiggins ** \\ Departments of Internal Medicine and Pathology, University of Michigan Medical School Ann Arbor, \\ MI 48109 (USA)
}

(Received June 1st, 1984; revision July 27th, 1984)

Key words: Albumin; Plasma; Polymer; Fragment

\section{Summary}

Nitrocellulose blots of normal human plasma proteins separated by sodium dodecyl sulfate-polyacrylamide gel electrophoresis were examined for polymeric complexes and fragments of albumin using an immunoperoxidase-labelled mouse monoclonal anti-human albumin antibody. Under reducing conditions, no polymeric complexes were seen. Under non-reducing conditions, polymeric complexes were detected at the following molecular weights: $210000,168000,147000,132000$, and 110000 . These probably represent both homo- and heteropolymers of albumin. Fresh plasma samples were also analyzed by S-200 chromatography with the same results indicating that detection of polymeric complexes was not an artifact of the sodium dodecyl sulfate-polyacrylamide gel electrophoresis technique. In quantitative terms, polymeric complexes constituted $0.3-2.8 \%$ of the total albumin present. Fragments of albumin were also seen in normal human plasma with molecular weights of 45000,28000 and 19000 . These fragments probably represent breakdown products of albumin in normal blood, and they constituted less than $2 \%$ of the total albumin present.

* This work has been published in abstract form from the Central Society for Clinical Research Meeting, Chicago, November, 1983.

** Correspondence to: Dr. Roger C. Wiggins, Internal Medicine (Nephrology), D3234 South Ambulatory Care Building, The University of Michigan, Ann Arbor, MI 48109, USA.

Abbreviations used: Sodium dodecyl sulfate, SDS; polyacrylamide gel electrophoresis, PAGE; phosphatebuffered saline, PBS. 


\section{Introduction}

Albumin is a nonglycosylated protein consisting of a single polypeptide chain of 582 amino acids with 33 cystine residues [1,2]. The molecule contains nine double loops formed by seventeen disulfide bridges arranged as three repeat units or domains [2,3]. Albumin molecules are heterogeneous in nature with respect to the free-SH group, consisting of both nonmercaptalbumins and mercaptalbumin. Nonmercaptalbumins are mixed disulfides between modified forms of mercaptalbumin with cysteine and glutathione [4]. Disulfide exchange within a single ablumin molecule also occurs [4]. Mercaptalbumin has a free-SH group readily titratable with SH reagent [4]. Oxidation of $\mathrm{SH}$ groups of mercaptalbumin results in polymerization by intermolecular disulfide exchange reactions [4]. Albumin is known to form homopolymers in vitro [5]. Whether or not polymers are present in blood is a subject of dispute [5]. Previous studies using purified albumin preparations have suggested that albumin polymers are not present in vivo [4,5].

\section{Methods}

Blood was obtained from four normal subjects after an 18-h fast. Blood samples were either placed in heparin $(10 \mathrm{U} / \mathrm{ml}$ final concentration) or sodium citrate $(0.38 \%$ final concentration), centrifuged, and the plasma applied to the gel or column within 5-10 min of drawing.

In different experiments, blood was drawn through metal needles or plastic cannulae. Serum samples were obtained by allowing blood to clot in a glass tube, immediately centrifuging, and applying fresh serum to the gel or column within 20 min of drawing.

\section{Monoclonal antibody production}

Monoclonal antibodies against human albumin were prepared. BALB/c mice were immunized with human albumin on three occasions over a 3-mth period. Spleen cells were fused with NS-I mouse myeloma cells according to Galfre et al [6]. Clones were screened using an ELISA assay system in which albumin was bound to the bottom of 96 well Immulon plates (Costar, Cambridge, MA, USA). Bound antibody was detected with alkaline phosphatase conjugated to rabbit anti-mouse antibody (Cappel Laboratories, Cochranville, PA, USA). Clones producing antialbumin antibody were subcloned by limiting dilution and then further screened for their ability to detect albumin which had been blotted from sodium dodecyl sulfate polyacrylamide gels (SDS-PAGE) onto nitrocellulose paper. Clone 9G7 was selected for its growth characteristics and because it recognized albumin blotted onto nitrocellulose paper following analysis by SDS-PAGE under both reducing and nonreducing conditions. Ascites fluid was obtained from pristane-pretreated mice into which clone $9 \mathrm{G} 7$ cells had been injected intraperitoneally (i.p.). For the experiments described, both spent culture medium and ascites fluid were used interchangeably. 


\section{SDS-PAGE and blotting}

SDS-PAGE was performed using a micromethod employing the agarose drop technique [7] for loading samples, and a Laemmli buffer system [8]. A discontinuous polyacrylamide gradient was employed capable of separating proteins in the range of 900000-9000 molecular weight. Protein was detected by the silver stain technique [9]. Proteins were blotted onto nitrocellulose paper by electrophoretic transfer using a Bio-Rad Transblotting cell (Bio-Rad Laboratories, Richmond, CA, USA). The transfer buffer was Tris $(25 \mathrm{mmol} / \mathrm{l})$, glycine $(192 \mathrm{mmol} / \mathrm{l})$, methyl alcohol $(20 \%$ $\mathrm{v} / \mathrm{v}), \mathrm{pH} 8.3$. The proteins were transferred at $110 \mathrm{~V}$ for $1-2 \mathrm{~h}$ in a refrigerated recirculating water bath. Following the transfer, the nitrocellulose paper (cut exactly to the size of the gel) was soaked overnight on a rotating mixer in phosphate-buffered saline containing $3 \mathrm{~g} / 100 \mathrm{ml}$ bovine serum albumin (BSA) and $100 \mathrm{ml} / 1$ goat serum. Mouse monoclonal antihuman albumin antibody was then added to the buffer for 1 h. The paper was then washed five times in PBS to remove unbound antibody. Peroxidase-conjugated rabbit anti-mouse antibody (Cappel Laboratories) at a final dilution of $1: 100$ in the $3 \mathrm{~g} / 100 \mathrm{ml} \mathrm{BSA}, 100 \mathrm{ml} / 1$ goat serum in PBS was incubated with the nitrocellulose blot on the rotating mixer at room temperature for $1 \mathrm{~h}$. Following successive washes in PBS the nitrocellulose blot was developed with $5,5^{\prime}$-diaminobenzedene $(1 \mathrm{mg} / 5 \mathrm{ml}$ in $0.1 \mathrm{~mol} / 1$ Tris $\mathrm{pH} \mathrm{7.4)}$ containing $0.02 \%$ $\mathrm{H}_{2} \mathrm{O}_{2}$. The reaction was stopped by washing out the reactants with deionized water.

\section{Quantitation by densitometry}

Bands identified by monoclonal anti-albumin antibody on nitrocellulose blots were quantitated by laser densitometry (LKB Instruments Inc., Gathersburg, MD, USA). A standard curve was linear over the range of 1-125 $\mathrm{ng}$ of albumin loaded onto the gel. The curve was used to calculate the relative amount of albumin in bands visualized in various dilutions of normal human plasma on the same blot (see Fig. 4). The amount of albumin in each band as a proportion of the total albumin present was calculated.

\section{Gel filtration experiments}

A $150 \times 1.5 \mathrm{~cm}$ column containing Sephacryl S-200 (Pharmacia Fine Chemicals, Division of Pharmacia Inc., Piscataway, NJ, USA) was packed at room temperature at a flow rate of $10 \mathrm{ml} / \mathrm{h}$ in a downward direction. The buffer system was $0.1 \mathrm{~mol} / \mathrm{l}$ phoshate containing $0.15 \mathrm{~mol} / 1 \mathrm{NaCl}$ and $0.02 \%$ sodium azide. The eluate from the column was collected in $0.5 \mathrm{ml}$ fractions.

\section{Results}

The proteins in fresh plasma or serum were separated on an SDS-PAGE system under both reducing and nonreducing conditions. The gel was then blotted onto nitrocellulose paper (see 'Methods'). Albumin was identified by an immunoperoxidase technique employing a mouse antihuman albumin monoclonal antibody (see 'Methods'). As shown in Fig. 1, the major band detected by the monoclonal antibody was seen at 60000 molecular weight under nonreducing conditions (Fig. 
1B) and at 67000 molecular weight under reducing conditions (Fig. 1E). This corresponded with the major band seen in normal human plasma run on the same gel and silver stained (Fig. 1A and D). Analysis of blots where spent culture medium was incubated with the blot instead of anti-albumin antibody showed no detectable bands in most experiments (Fig. 1C and F), although occasionally a faint band was visualized at the 160000-180000 molecular weight position corresponding to IgG.

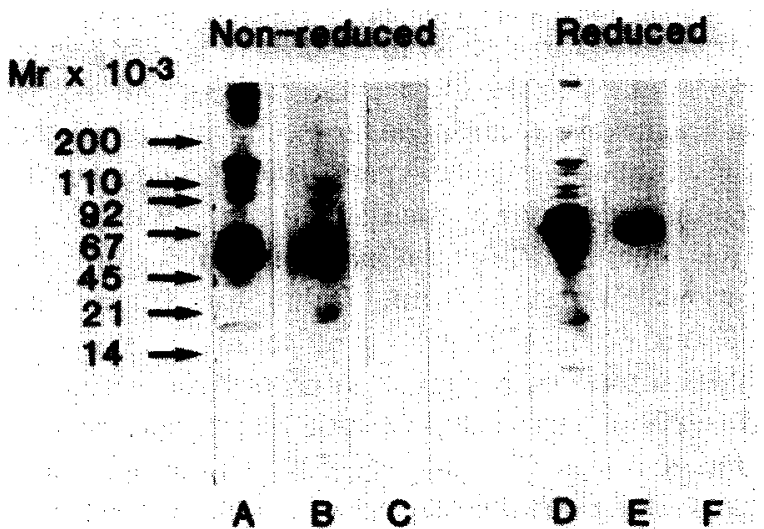

Fig. 1. Normal human plasma ( $1 \mathrm{ml}$ of a $1 / 30$ dilution of plasma) analyzed by SDS-PAGE under the following conditions. $\mathrm{A}=$ nonreduced, silver stain; $\mathrm{B}=$ nonreduced, blotted onto nitrocellulose paper, stained with monoclonal mouse anti-albumin antibody and peroxidase-labelled anti-mouse IgG antibody to show albumin; $\mathrm{C}=$ nonreduced, stained with peroxidase-labelled anti-mouse IgG antibody alone; $\mathrm{D}=$ reduced, silver stain; $\mathrm{E}=$ reduced, stained with monoclonal mouse anti-albumin antibody and peroxidase-labelled anti-mouse $\mathrm{IgG}$ antibody to show albumin; $\mathrm{F}=$ reduced, stained with peroxidaselabelled antimouse IgG antibody alone.

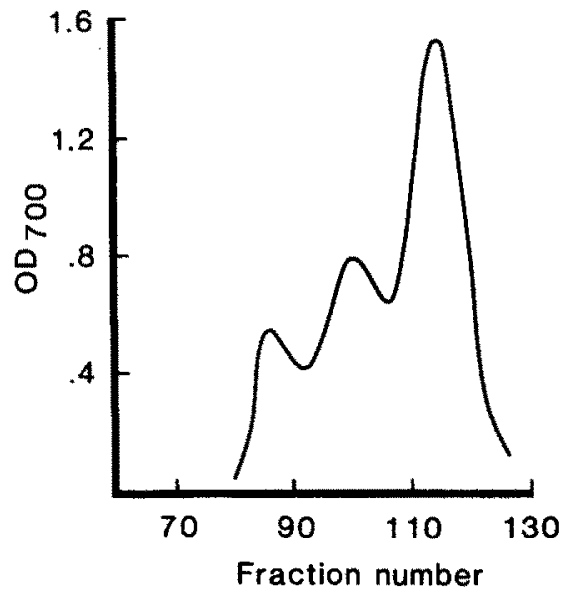

Fig. 2. Sephacryl-200 chromatogram of $0.5 \mathrm{ml}$ normal human plasma. The buffer system was $0.1 \mathrm{~mol} / 1$ phoshate, pH 7.4, containing $0.15 \mathrm{~mol} / \mathrm{A} \mathrm{NaCl} .0 .5 \mathrm{ml}$ fraction was collected. The first peak at fraction 85 corresponds to the void volume. 
This was probably due to the anti-mouse antibody cross-reacting with human IgG on the blot. The nonreduced blot of human plasma stained for albumin also showed higher and lower molecular weight bands (28000 and 19000) (Fig. 1B). These findings were consistent in many different experiments. The result did not vary whether the sample was plasma or serum, or whether blood was obtained via a plastic or metal needle, or was analyzed minutes or hours after drawing the blood. The findings suggested that high and low molecular weight forms of albumin might exist in plasma. However, the alternative possibility existed that mixing plasma with

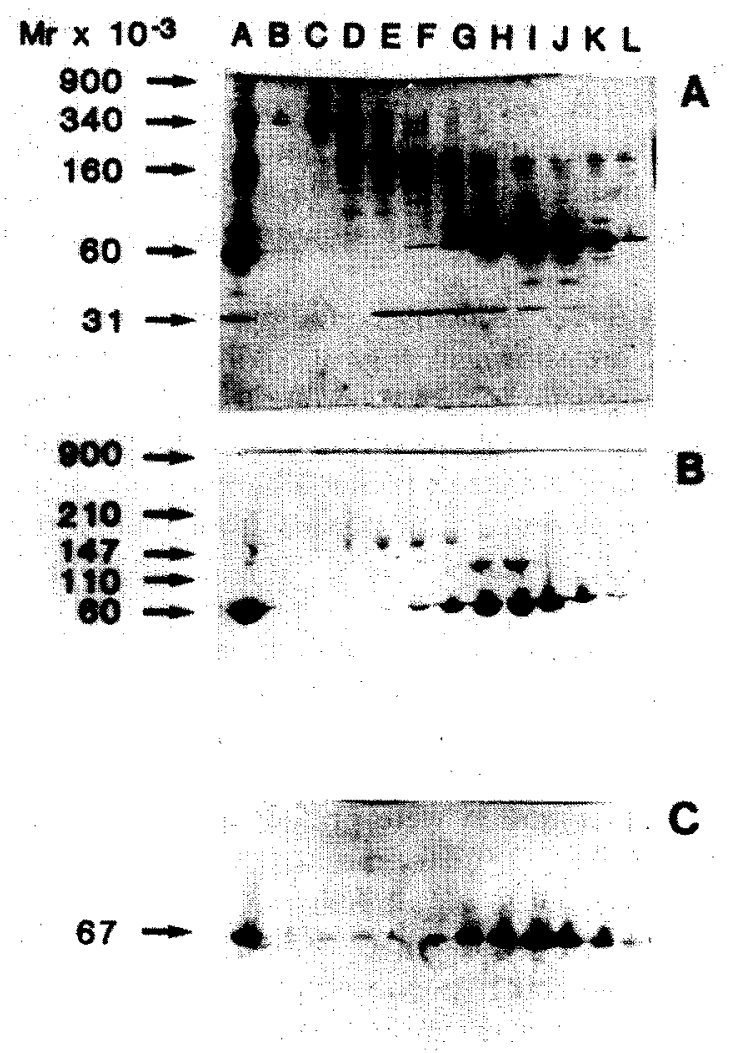

Fig. 3. SDS-PAGE analysis of fractions from an S-200 chromatogram as shown in Fig. 2. A gel (A) run under nonreducing conditions has been silver stained for protein. Two similar gels run under nonreducing (B) and reducing $(C)$ conditions have been blotted and peroxidase-stained for albumin as described in 'Methods'. In each case, lane A contains normal human plasma. Lanes B through $L$ contain fractions 80 , $85,90,95,100,105,110,115,120,125,130$ from the S-200 chromatogram. Blot B shows that the major albumin peak (seen at 60000 molecular weight under nonreducing conditions) is in fractions $F$ through $K$. However, in fraction $D$ through $G$ there are high molecular weight (approximately 147000 molecular weight) forms of albumin. Faintly seen in this gel, and seen in other gels, are additional higher molecular weight species seen in earlier fractions. Blot $\mathrm{C}$ run under reducing conditions shows bands staining for albumin in all fractions from the S-200 chromatogram (B through L). Thus, reduction of disulfide bands liberated albumin to migrate at its native molecular weight $(67000)$ even in the high molecular weight fractions (B through D) eluted from the S-200 column. 
SDS/urea prior to running the gel might cause albumin polymerization and give rise to the observed results. To address this question, fresh plasma was run over an S-200 column to separate proteins on the basis of size prior to mixing with SDS/urea. The protein profile of an S-200 column is shown in Fig. 2 with the three characteristic peaks of high molecular weight (Fibrinogen, IgM), intermediate moelcular weight (IgG) and the albumin peak. SDS-PAGE analysis of column fractions run under nonreducing conditions and stained for protein is shown in Fig. 3A, confirming that separation of proteins occurred according to their size. Albumin as identified by monoclonal antibody under nonreducing condition is shown in Fig. 3B. The major band is at 60000 molecular weight and corresponds to the portions of native albumin on the stained gel. Higher molecular weight material is detected by the albumin monoclonal antibody seen in earlier fractions corresponding to the higher molecular weight bands seen in Fig. 1. These data show that high molecular weight forms of albumin in plasma are not the result of mixing the plasma with SDS/urea and imply that these higher molecular weight forms of albumin were present in plasma at the time of blood drawing.

The column fractions of plasma run under reducing condition and blotted for albumin with the monoclonal antibody are shown in Fig. 3C. Albumin at native molecular weight $(67000)$ is seen even in fractions corresponding to high molecular weight proteins. These results show that the albumin present at high molecular weight was probably at least partially disulfide-linked to other albumin molecules or to other proteins. The same results were obtained with plasma from four normal individuals.

\section{Quantitation and analysis of high molecular weight forms of albumin in plasma}

Fresh plasma samples and commercially available purified human albumin were run under nonreducing conditions and blotted onto nitrocellulose paper. Albumin was identified by monoclonal anti albumin antibody (Fig. 4). The bands common to both plasma and the purified albumin preparation were present at the following molecular weights $(210000,147000,132000,110000$, and 60000$)$. These bands probably correspond to albumin and polymers of albumin (dimers and other multimers). Since albumin fragments were also present $(28000,19000$ molecular weights) the possibility exists that albumin might polymerize with albumin fragments giving rise to bands in positions not seen with purified albumin preparation in Fig. 4. Alternatively, complexes of albumin linked by disulfide bonds to other proteins might explain these findings.

Quantitation of the amount of albumin present in polymeric form was attempted. Five-fold dilutions of purified albumin and plasma were analyzed on the same gel (Fig. 4). The blots were then scanned with a laser densitometer. A standard curve was constructed for the major band in the purified albumin preparation. This was linear over the range 1-125 ng albumin loaded onto the gel. From this standard curve, the proportion of the total amount of albumin present in each band and in the native peak from the plasma samples was estimated. The results were expressed as the proportion of albumin molecules present as polymer. In fasting fresh plasma from four normal individuals the results varied between $0.3-2.8 \%$ of the total 
albumin being present as polymer. Albumin fragments constituted $<2 \%$ of the total albumin in plasma.

\section{Discussion}

In this study, a mouse monoclonal antibody raised against human albumin was used as a probe to detect albumin molecules in plasma where the proteins had been separated according to their size by SDS-PAGE. Analysis of fresh normal human plasma or serum by this method showed the presence of both high and low molecular weight forms of albumin. If the plasma was treated with reducing agent prior to gel separation most of the high molecular weight form disappeared, indicating that the high molecular weight albumin molecules were mostly present in disulfide-linked polymer form.

Because of the possibility that mixing plasma with SDS/urea might itself promote polymerization, the proteins in fresh citrated plasma were also separated by S-200 column chromatography prior to analysis by SDS-PAGE blotting system for albumin detection. High molecular weight forms of albumin were eluted from the S-200 column at a position appropriate to their molccular size indicating that polymerization was not an artifact of the analytical method. Furthermore, the appearance of high molecular weight forms and fragments did not appear to be affected by the conditions used to obtain the blood (plastic or metallic needle, plasma or serum, immediate analysis of fresh plasma or plasma kept for several hours). We, therefore, conclude that high molecular weight forms of albumin were present in blood of normal individuals at the time the blood was drawn.

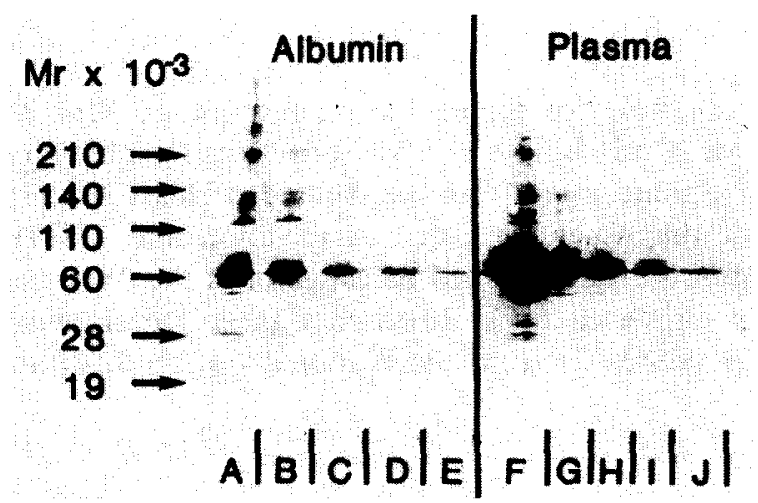

Fig. 4. Albumin blot of SDS-PAGE-separated proteins from a purified albumin preparation and normal human plasma. Albumin $(1 \mathrm{mg} / \mathrm{ml})$ and plasma $(1 \mathrm{ml}$ of a $1 / 30$ dilution) were run in lanes $A$ and $F$, respectively. In each case, serial 5-fold dilutions of the albumin and plasma were run in lanes $B$ through $E$ and $G$ through $J$, respectively. Lane A clearly shows multiple high molecular weight polymers some of which correspond to bands seen in plasma (lane F). However, there are bands in plasma not seen in purified albumin, possibly representing albumin heteropolymers. Low molecular weight forms of albumin seen in plasma (lane F) mostly correspond to low molecular weight forms seen in the purified albumin preparation (lane A). With serial dilution (B through $E$ and $G$ through $J$ ) only the 60000 molecular weight species of native albumin is seen. These and similar blots were scanned using a laser densitometer to calculate the relative amounts of albumin present in polymeric and fragmented forms (see 'Methods'). 
Albumin molecules are well known to form disulfide-linked homopolymers in vitro [10]. The question of whether these forms of albumin are present in vivo has not been resolved, although it has been estimated that, if present, polymers of albumin constitute $<2 \%$ of the total albumin present [10]. Purified albumin, especially when heat treated, lyophilized and following storage polymerizes to some extent [5]. Polymerization in vitro is caused by oxidants and occurs particularly in the presence of iron and copper [11]. Defatted albumin is especially susceptible to polymer formation, and fatty acids prevent polymerization [12]. In contrast heteropolymers or complexes of albumin with other proteins through disulfide interchange is well described. Such examples include IgA [13], IgM [14,15], Bence Jones protein, prealbumin and $\alpha_{1}$-antitrypsin [16], $\alpha$-lipoprotein [17], and amyloid A protein [18]. The positions of the bands seen in Fig. 4 in relation to those of the purified albumin preparation would favor at least some of the albumin being in homopolymer form, but this has not been proven.

The effect of albumin polymerization on the various different functions of albumin is unknown. In this study we have provided evidence that a small proportion of albumin in blood from normal individuals is in polymer form $(0.3-3.8 \%)$. Since albumin constitutes more than half the protein in plasma $(40 \mathrm{mg} / \mathrm{ml})$, this means that albumin polymer is present at $100 \mu \mathrm{g} / \mathrm{ml}$ or more. Whether this amount of polymer has a particular function or whether the amount might be changed in clinical circumstances, such as oxidant production by activated inflammatory cells or the increases in albumin turnover seen in nephrotic syndrome, requires further study.

\section{Acknowledgements}

We are grateful to Ms. Elizabeth Reid for typing the manuscript, to Mrs. M. Marshall for the artwork, and to Mr. Craig Biddle and Mr. Ed Burns for photography. This work was supported by a grant-in-aid from the American Heart Association and the Michigan branch of the American Heart Association and USPHS Grant AM 30673. Dr. Roger Wiggins is an Established Investigator of the American Heart Association. Dr. Wilson is supported by a Research Cancer Development award (PHS Grant No. 5K04 CA 00845-02) from the National Cancer Institute, DHHS.

\section{References}

1 Behreins PO, Spiekerman AN, Brown JR. Structure of human serum albumin. Fed Proc 1975; $34: 591$.

2 Brown JR. Structure of bovine serum albumin. Fed Proc 1975; 34: 591.

3 Brown JR. Structure of serum albumin: disulfide bridges. Fed Proc 1974; 33: 1389.

4 Anderson LO. Heterogeneity of bovine serum albumin. Biochim Biophys Acta 1966; 117; $115-133$.

5 Kistler P. Acceptability of albumin polymers in albumin preparation. 13th International Congress of IABS, Budapest 1973, Part A: Purification of Proteins Development of Biological Standard, Vol 27, Basel: Krajer, 1974: 196-199.

6 Galfre $\mathrm{G}$, Howe SC, Milstein C. Antibodies to major histocompatibility antigens produced by hybrid cell lines. Nature (London) 1977; 266: 550-552. 
7 Wiggins RC. Agarose drop method for loading thin polyacrylamide gels. Anal Biochem 1982; 126: $422-424$.

8 Laemmli UK. Cleavage of structural proteins during assembly of the head of bacteriophage $\mathrm{T}_{4}$. Nature (London) 1970; 227: 680-685.

9 Merril CR, Switzer RC, Van Keuven ML. Trace polypeptides in cellular extracts and human body fluids detected by two-dimensional electrophoresis and a highly sensitive silver stain. Proc Natl Acad Sci USA 1979; 76: 4335-4339.

10 Friedli H, Kistler P. Polymers in preparation of human serum albumin. Vox Sang 1970; 18: 542-546.

11 Everett WW. The effect of metal ions on the isomerization and dimerization of bovine plasma albumin. J Biol Chem 1963; 238: 2676-2683.

12 Anderson L. Reduction and reoxidation of disulfide bonds of bovine serum albumin. Arch Biochem Biophys 1969; 133: 277-285.

13 Baumstark JS. Guidelines for the preparative fractionation of human serum proteins on gradient eluted columns of concavatin A-sepharose: elution positions of fourteen well characterized proteins and evidence for concavatin A-reactive albumin IgA and IgG complexes. Prep Biochem 1983; 13: 315-345.

14 Ropars C, Donicl CH, Salenn JP. Fixation of albumin to the hinge region of a macroglobulin. Biomedicine 1973; 19: 228-230.

15 Harboe M, Folling I. Complex formation between monoclonal IgM and albumin. Scand J Clin Lab Invest 1974; 3: 51-60.

16 Laurell C-B, Thulin E. Thiol disulfide interchange in the binding of Benee Jones proteins to $\alpha_{1}$-antitrypsin, prealbumin and albumin. J Exp Med 1975; 141: 453-465.

17 Wille LE, Torsvik H, Kierulf P, Ajone E. Studies on the pre $\alpha$-lipoprotein of human serum. Scand J Clin Lab Invest 1977; 37: 545-549.

18 Rosenthal JC, Franklin EC. Serum amyloid A (SAA) protein-interaction with itself and serum albumin. J Immunol 1977; 119: 630-634. 